OPEN ACCESS

Edited by:

Yanghua Tian

First Affiliated Hospital of Anhui

Medical University, China

Reviewed by:

Deniz Doruk,

Mayo Clinic, United States

Lindsay M. Oberman,

National Institute of Mental Health,

National Institutes of Health $(\mathrm{NIH})$,

United States

*Correspondence: Karin Prillinger

karin.prillinger@meduniwien.ac.at

Specialty section:

This article was submitted to Neuroimaging and Stimulation,

a section of the journal

Frontiers in Psychiatry

Received: 14 March 2021

Accepted: 26 July 2021

Published: 30 August 2021

Citation:

Prillinger K, Radev ST, Amador de Lara G, Klöbl M, Lanzenberger R, Plener PL, Poustka $L$ and Konicar $L$

(2021) Repeated Sessions of Transcranial Direct Current Stimulation

on Adolescents With Autism Spectrum Disorder: Study Protocol for a Randomized, Double-Blind, and

Sham-Controlled Clinical Trial.

Front. Psychiatry 12:680525. doi: 10.3389/fpsyt.2021.680525

\section{Repeated Sessions of Transcranial Direct Current Stimulation on Adolescents With Autism Spectrum Disorder: Study Protocol for a Randomized, Double-Blind, and Sham-Controlled Clinical Trial}

\author{
Karin Prillinger ${ }^{1 *}$, Stefan T. Radev 1,2, Gabriel Amador de Lara ${ }^{1}$, Manfred Klöb/3, \\ Rupert Lanzenberger ${ }^{3}$, Paul L. Plener ${ }^{1,4}$, Luise Poustka ${ }^{5}$ and Lilian Konicar ${ }^{1}$ \\ ${ }^{1}$ Department of Child and Adolescent Psychiatry, Medical University of Vienna, Vienna, Austria, ${ }^{2}$ Institute of Psychology, \\ University of Heidelberg, Heidelberg, Germany, ${ }^{3}$ Department of Psychiatry and Psychotherapy, Medical University of Vienna, \\ Vienna, Austria, ${ }^{4}$ Department of Child and Adolescent Psychiatry and Psychotherapy, University of Ulm, Ulm, Germany, \\ ${ }^{5}$ Department of Child and Adolescent Psychiatry and Psychotherapy, University Medical Center Göttingen, Göttingen, \\ Germany
}

Background: Social-emotional difficulties are a core symptom of autism spectrum disorder (ASD). Accordingly, individuals with ASD have problems with social cognition such as recognizing emotions from other peoples' faces. Various results from functional magnetic resonance imaging and electroencephalography studies as well as eye-tracking data reveal a neurophysiological basis of these deficits by linking them to abnormal brain activity. Thus, an intervention targeting the neural origin of ASD impairments seems warranted. A safe method able to influence neural activity is transcranial direct current stimulation (tDCS). This non-invasive brain stimulation method has already demonstrated promising results in several neuropsychiatric disorders in adults and children. The aim of this project is to investigate the effects of tDCS on ASD symptoms and their neural correlates in children and adolescents with ASD.

Method: This study is designed as a double-blind, randomized, and sham-controlled trial with a target sample size of 20 male participants (aged 12-17 years) diagnosed with ASD. Before randomization, the participants will be stratified into comorbid depression, comorbid ADHS/conduct disorder, or no-comorbidity groups. The intervention phase comprises 10 sessions of anodal or sham tDCS applied over the left prefrontal cortex within 2 consecutive weeks. To engage the targeted brain regions, participants will perform a social cognition training during the stimulation. TDCS-induced effects on ASD symptoms and involved neural circuits will be investigated through psychological, neurophysiological, imaging, and behavioral data at pre- and post-measurements. Tolerability will be evaluated using a standardized questionnaire. Follow-up assessments 1 and 6 months after the intervention will examine long-lasting effects. 
Discussion: The results of this study will provide insights into the changeability of social impairments in ASD by investigating social and emotional abilities on different modalities following repeated sessions of anodal tDCS with an intra-simulation training. Furthermore, this trial will elucidate the tolerability and the potential of tDCS as a new treatment approach for ASD in adolescents.

Clinical Trial Registration: The study is ongoing and has been registered in the German Registry of Clinical Trials (DRKS00017505) on 02/07/2019.

Keywords: autism spectrum disorder, transcranial DC stimulation, clinical trial, social cognition, neuromodulation

\section{INTRODUCTION}

One out of 54 children fulfills the diagnostic criteria for autism spectrum disorder (ASD) (1), with boys being affected three to four times as often as girls (2). ASD is a neurodevelopmental disorder characterized by social and communicative deficits and repetitive, stereotyped behaviors, ranging over a wide spectrum with different degrees of impairment [International Classification of Diseases ICD-10; (3)].

As there is currently no cure for ASD, psychosocial and pharmacological treatments share the aim to ameliorate the core symptoms and enable a life as independent as possible (4). Psychosocial interventions show positive effects on intellectual and adaptive functioning (5), but suffer from limited support from randomized controlled trials (RCTs). Strongest evidence exists for the effectiveness of interventions that focus on early parent-child interactions $(6,7)$. Furthermore, there is no pharmacological treatment for the core symptoms of ASD and medication is mainly used for the therapy of commonly co-occurring disorders such as attention-deficit/hyperactivity disorder (ADHD) or depression (6). The need for efficient and affordable new treatment methods also becomes evident when assessing quality of life, employment, independency, social relationships, and mental and physical health in adults with ASD, which were found to be poor despite average cognitive functioning $(8,9)$. Thus, specifically targeting the mechanisms underlying the social-emotional dysfunctions in ASD can form the basis of new and viable treatment methods.

Social-emotional difficulties include pronounced impairments in empathy, a central prerequisite for social interactions. To be able to understand what others are feeling and to react appropriately to their emotions, it is often necessary to recognize the expressed emotion from others' faces. The ability to discriminate the six basic emotions (happy, sad, fear, anger, disgust, and surprise) is usually acquired in the first year of life (10), whereas the ability to discriminate more complex emotions improves until adulthood (11). It has been repeatedly shown that people with ASD have a deficit in the ability to recognize the emotions of others $(12,13)$. Moreover, results from neurological and electrophysiological studies show clear differences in automatic emotion recognition processes between ASD and typically developing children (14).

Another factor influencing social interactions is the direction of gaze (15). Eye-tracking reveals that children with ASD show aberrant patterns of gaze and fixation times when seeing human faces $(16,17)$ and eye gaze abnormalities have even been proposed as a robust biomarker for ASD (16). Moreover, dysfunctions in several brain regions including the dorsolateral prefrontal cortex (DLPFC) are involved in the development of this aberrant gaze behavior. In typically developing individuals, direct gaze leads to an enhanced response in brain areas important for empathic processes like theory of mind (ToM). In contrast, individuals with ASD show the same response when the gaze is averted and respond to direct gaze with an abnormal activation of the ToM network [medial prefrontal cortex (MPFC), temporoparietal junction, posterior superior temporal sulcus region, and amygdala] (15). These regions are also part of the social brain network (SBN) $(18,19)$.

Research regarding the neural underpinnings of behavioral social problems in ASD found evidence for alterations within the SBN in structural and functional magnetic resonance imaging (MRI) studies (20). Furthermore, structural MRI studies showed abnormalities in gray matter volume and white matter structure in short-distance tracts in the SBN, as well as an association between these abnormalities and social malfunctioning in ASD (21-24). Task-related fMRI studies in individuals with ASD revealed atypical activity and connectivity in social brain regions during the processing of social stimuli (25). For instance, processing of emotional facial expressions was associated with reduced activity in several brain regions important for interpersonal interactions, including the amygdala, MPFC, ventrolateral prefrontal cortex, and superior temporal sulcus region in individuals with ASD compared with typically developing individuals (26). Neuroimaging results show that the most consistently activated brain regions in ToM tasks are the medial prefrontal and orbitofrontal cortices (27). Within the ToM network, reduced functional connectivity in persons with ASD was detected (15). In detail, the functional connectivity between the MPFC and the posterior cingulate cortex (PCC) has repeatedly been shown to be lower in individuals with ASD (28, 29). A weaker connectivity between these regions is correlated with more serious social impairments [see (29)]. Both the MPFC and the PCC are part of the default mode network (DMN), which is involved in complex emotional and social processes such as ToM and self-referential thoughts $(30,31)$. Functional connectivity of DMN regions has been shown to be altered at rest and reduced in several social tasks such as face processing in adolescents and adults with $\operatorname{ASD}(28,32)$. While the functional 
connectivity between the DMN nodes normally increases with age, the development of long-distance functional connectivity in the DMN cannot be observed in adolescents with $\operatorname{ASD}(28,33)$. Also, brain regions important for social interactions outside the DMN exhibit reduced activity and functional connectivity during resting state (20). Individuals with ASD showed, compared with typically developing individuals, a weaker functional connectivity between the amygdala and the ventromedial prefrontal cortex (34) and a reduced connectivity within the lateral occipital cortex, which was associated with symptom severity (35). Thus, it appears that neurophysiologically based interventions should target the MPFC as a potential mediator for the reduction of ASD symptoms.

Contrary to fMRI, electroencephalography (EEG) allows for calculating the functional connectivity of the brain based on absolutely quantifiable rather than relative measures. In ASD, resting-state EEG studies suggest a reduced long-range connectivity between frontal lobe and other cortical regions and short-range overconnectivity $(36,37)$. Regarding frequency bands, decreased power in alpha is the most consistent finding $(36,38)$, which is thought to be associated with inhibitory control deficits in ASD (36).

Neuromodulation constitutes, alongside psychosocial interventions and psychopharmacology, the third pillar of therapeutic interventions in psychiatry. Transcranial direct current stimulation (tDCS) in particular is a non-invasive neurophysiological method, which has the potential to modify brain function by affecting neuronal resting membrane potentials $(39,40)$. It affects neuronal excitability on a sub-threshold level without eliciting action potentials (40-42). Depending on the goal of the intervention, anodal or cathodal stimulation can be used to either enhance or reduce neuronal excitability and thereby modulate processes related to the target brain region in the desired direction (43). The effects of direct current stimulation elicits a polarity-dependent facilitation or inhibition of the spontaneous neuronal firing rate $(40,43,44)$. Poststimulation effects of tDCS are contingent on the duration of the stimulation and last from several minutes up to some hours $(40,45)$. Studies investigating the effects of tDCS on neural activity showed that direct current can modulate cortical connectivity in the brain (46) and induce changes in the alpha frequency band during and after the stimulation (47-49). Moreover, fMRI studies found changes in brain connectivity in both task-related and resting-state networks after the application of tDCS (50-53). Brain stimulation is more effective and causes more long-lasting plastic changes in already activated neural circuits (54). Additionally, aftereffects of tDCS were shown to depend on the emotional and physiological state during stimulation (41). Given these findings, intra-stimulation engagement tasks are used to enhance the effects of tDCS [e.g., $(55,56)]$.

Therapeutically, tDCS is used to alter local neuronal excitability that is assumed to be in a dysfunctional hypo- or hyperactive state (45). Effects of the stimulation expand by changes in the neural network into more distant regions and lead to reorganization of neuronal circuits $(45,57)$. Due to encouraging results in the treatment of various neuropsychiatric disorders in adults (58-61), tDCS has gained attention in the treatment of childhood and adolescent neuropsychiatric disorders over the past years $(45,62-64)$.

Regarding the use of tDCS in children with ASD, 12 articles have been published to date (65-76). Among these, four are randomized, double-blind, sham-controlled studies; the remaining articles comprise experimental, quasi-experimental, and pilot studies, a case series, and a case study. Outcome measurements, number and details of stimulation sessions, and control conditions vary across the studies [for reviews see $(77,78)]$. Therefore, the current evidence is sparse and methodologically incomparable (79). Nevertheless, these studies point toward positive effects of tDCS in the treatment of ASD showing an improvement in ASD symptoms such as socialization, sensory awareness, repetitive behaviors, and behavioral problems $(65,68,70,76)$ as well as in cognitive abilities often impaired in individuals with $\operatorname{ASD}(71,74)$. The available results not only provide indications for significant symptom reductions maintained for 6 months (68) but also emphasize the necessity of further research $(70,79)$. The potential of tDCS to counteract ASD-specific aberrant brain activity was highlighted by studies showing modulation of long-distance connectivity (66), an increase in functional connectivity in the alpha band $(68,80)$, increasing connectivity between the hemispheres within alpha and induced neuroplastic changes (75). Moreover, studies report a reduction in ASD symptoms that were associated with an increase in the peak alpha frequency band in resting-state EEG (76) and increasing EEG complexity (72) after tDCS stimulation. These studies as well as the majority of the present tDCS studies in children and adolescents with ASD report reduced ASD symptoms after anodal stimulation with the anode placed over the DLPFC (77). However, none of the studies used a simulationbased approach to evaluate the peak magnitudes of the electric fields and to define the stimulation target. TDCS applied over this commonly used stimulation site is able to increase the functional connectivity between the MPFC and the PCC in healthy adults (51) as well as in individuals with ASD (81). Taken together, both theoretical considerations and empirical findings regarding the pathophysiological signature of ASD lead to the proposition that tDCS can be used to alter dysfunctional patterns of brain activity.

The goal of the present study is to investigate the clinical and scientific significance of tDCS for improving social cognition abilities in ASD with a clear neurobiological rationale. Therefore, the planned study will (1) examine tDCS-related changes on reported symptomatic changes, behavior, brain activity, and connectivity; and (2) explore the long-term effects of tDCS in ASD and thereby evaluate tDCS as a cost-effective, time-efficient treatment option for children and adolescents with ASD.

\section{METHODS AND ANALYSIS}

The study is designed as a randomized, double-blind, shamcontrolled clinical trial with two follow-up measurements 1 and 6 months after the last stimulation session, respectively. 


\section{Participants}

Measurements and interventions will be carried out at the Department of Child and Adolescent Psychiatry at the Medical University of Vienna, Austria. The participants will be recruited from the outpatient clinic and from local institutes for individuals with ASD.

\section{Sample Size Calculations}

Power analysis was done with $\mathrm{G}^{*}$ Power version 3.1.9.2 (82) to detect a difference in the primary outcome [SRS, (83)] calculating repeated measures ANOVA considering an effect size $f$ of 0.25 , a power of $80 \%$, and an $\alpha$ of 0.05 . Previous studies in children with ASD have shown larger effect sizes for tDCS (63). A sample size of 20 participants $(N=20)$ will be necessary to report medium effect sizes on the primary outcome. Analyses of secondary outcomes were not included in the power analysis and therefore considered underpowered.

\section{Randomization}

A total of 20 male participants will be included. To balance the experimental and control group with respect to comorbidities, all participants will be stratified into one of three subgroups based on their clinical presentation: subgroup A for participants without comorbidity, subgroup $\mathrm{B}$ for participants with depression as primary comorbidity, and subgroup $\mathrm{C}$ for participants with $\mathrm{ADHD}$ and/or conduct disorder as primary comorbidity. After subgroup stratification, the participants will be randomly allocated to the active condition or the sham condition by assigning a code to each participant. To ensure a quick study start for the participants after enrollment, a block randomization design will be used.

\section{Blinding}

The study mode of the stimulation device encodes sham and active stimulation using preprogramed codes so that the participant and investigators will be blind to the type of stimulation. The stimulation parameters (duration, fade-in, fadeout time, and current intensity) are set and saved on the device to avoid accidental modification of the parameters. To investigate the success of the subject-blinding, participants will be asked about their beliefs of the received stimulation type at the last stimulation session. After completing the 6-month follow-up measurement or after dropping out of the study, participants, and their caregiver will be informed about group allocation. Participants in the sham condition will not receive active stimulation after the end of the trial. Premature unblinding using prepared envelopes can be performed when knowledge of the actual group allocation becomes necessary for the safety of the patient. The blinding, code storage, and preparation of code-break envelopes will be done by a staff member not directly involved in the intervention and the day-to-day management of the study.

\section{Inclusion Criteria}

Participants eligible for the trial must comply with all of the following:

- Male
- Fulfilling ICD-10 criteria for ASD and diagnosed with ASD from a trained professional using the Autism Diagnostic Interview-Revised [ADI-R; (84)] and/or the Autism Diagnostic Observation Schedule [ADOS 2; (85)]

- Age between 12 and 18 years

- Right-handed

- $\mathrm{IQ} \geq 70$ assed using standardized instruments

- Treatment-naive to neurostimulation

- Signed written informed consent of the participant and primary caregiver.

\section{Exclusion Criteria}

- Contraindications for tDCS such as cardiac pacemakers, defibrillator, cochlear implant, intracranial/cranial stimulators, and other metals in the head

- Contraindications for MRI

- Epilepsy or related seizure disorders

- Other severe neurologic or psychiatric disorders or medical conditions (e.g., skull defect and craniotomy)

- Concomitant psychopharmacological medication.

Ongoing concomitant social or psychotherapeutic long-term interventions must be held constant during the course of the intervention.

\section{Intervention}

The intervention phase comprises 10 sessions of tDCS or sham stimulation within two consecutive weeks, with a 2-day break after the fifth session (see Figure 1 for study overview). If feasible for the participant, all stimulation sessions will be held at the same time of the day. In each session, prior to the stimulation, the participant will complete a brief questionnaire about general well-being, attention, motivation, and experiences before the session. Afterwards, two rubber electrodes with conductive paste will be attached to the head of the participant. To decide on the optimal stimulation parameters, an MRI-based finite-element model approach was utilized, which simulates the intensity, distribution, and focality of the electric field induced by tDCS. To this aim, SimNIBS 3.1 (86) and structural T1 images of adolescents with ASD from a previous clinical trial executed by our research group were used. The parameters under comparison comprised an intensity of $2 \mathrm{~mA}$, three different electrode sizes (3 $\times 3,5 \times 5$, and $5 \times 7 \mathrm{~cm}$ rectangular rubber electrodes) and two different conductors ( $\mathrm{NaCl}$ solution and Ten 20 paste).

Simulations demonstrated peak intensity of electric fields showing stronger fields with smaller electrodes $(3 \times 3 \mathrm{~cm})$ and conductive Ten 20 paste. Here, stimulating anodal tDCS over the left DLPFC would lead to peak magnitudes at the MPFC (see Figure 2), which match with the targeted neural circuit. This stimulation setup is in line with the recommendations suggested in a recent systematic review and meta-analysis on the existing literature of tDCS in ASD (77) and with other studies demonstrating effects of tDCS on reducing ASD symptoms. Therefore, an electrode montage with the anode over the left DLPFC (F3 according to the international 10-20 system for EEG) and the cathode over the right supraorbital region will be used in the current trial. 


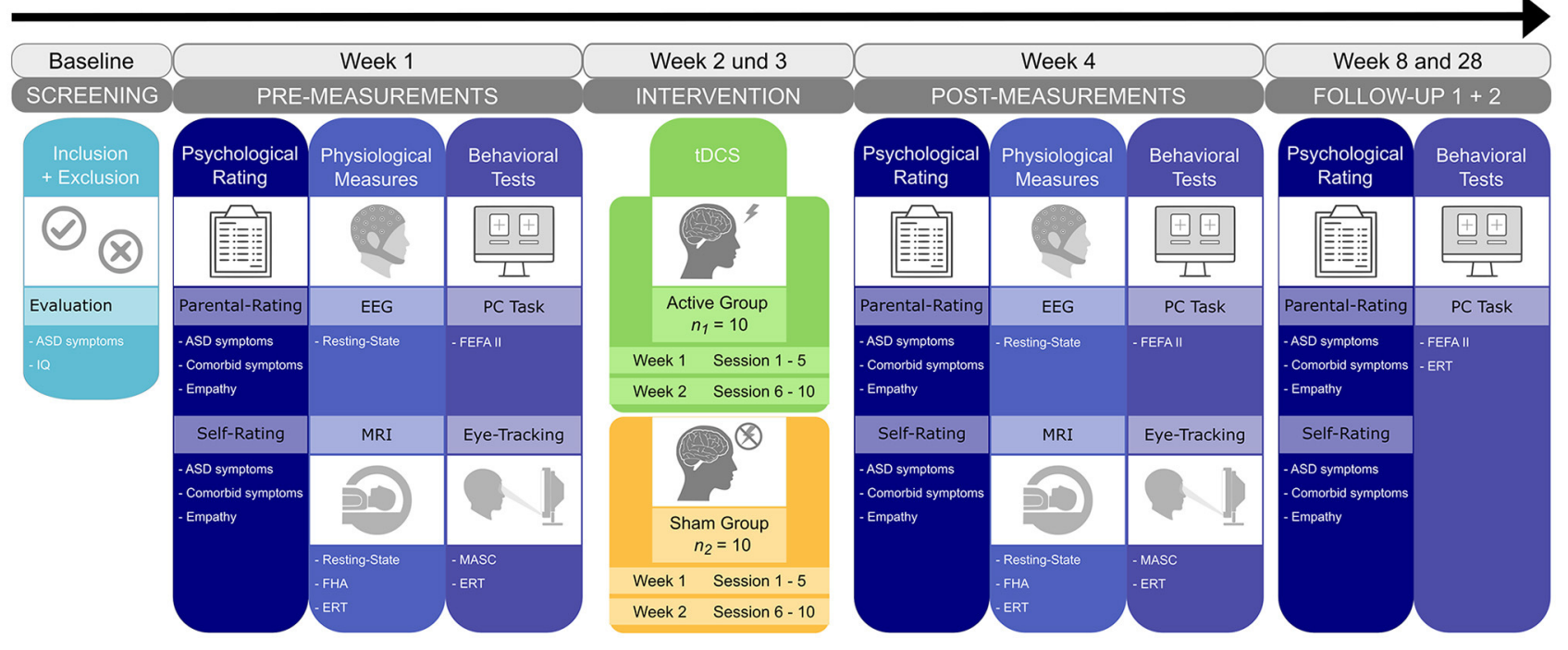

FIGURE 1 | Study timeline and overview. After enrollment, participants will undergo a set of psychological, behavioral, and physiological baseline measures in the first week. Following randomization, 10 sessions of either active or sham tDCS will be conducted within a 2-week interval. Post-treatment measures are repeated on the subsequent week. Two follow-up measures are planned 1 and 6 months after the end of the tDCS intervention. ERT, emotion recognition task; FEFA II, frankfurter test and training for recognizing facial affect; FHA, frith-happé animations; MASC, movie for the assessment of social cognition.

To localize the electrode site F3, the Beam F3 system (87) will be used. Anodal tDCS will be administered through an EldithDC Stimulator (NeuroConn GmbH, Germany) at $2 \mathrm{~mA}$ current strength for $20 \mathrm{~min}$ with a fade-in and fade-out of $30 \mathrm{~s}$ at the start and end of the stimulation. During the sham stimulation, a fadein phase of $30 \mathrm{~s}$, followed by $40 \mathrm{~s}$ of $2 \mathrm{~mA}$ stimulation and a fadeout phase of $30 \mathrm{~s}$ will be applied. The participants will experience the typical skin sensation usually produced at the beginning of an active tDCS stimulation and are therefore expected to remain unaware of the real condition (88).

\section{Safety and Adverse Events}

As for potential risks of $\mathrm{tDCS}$, guidelines report no serious adverse events in over 18,000 sessions of low-intensity transcranial electrical stimulation in pediatric and adult patients, as well as in healthy subjects (89). Current data also specifically emphasize the feasibility, tolerability, and safety of tDCS in children and adolescents $(45,63,90)$. Adverse effects of tDCS in children and adolescents were described as mild and transient, including tingling (11.5\%), itching (5.8\%), redness $(4.7 \%)$, and scalp discomfort (3.1\%) (91). Thus, when guidelines are followed, tDCS is a safe modality for children and adolescents with various neurological conditions (92). The proposed parameters of this study (including electrode size, current strength, and duration) were previously tested for their safety in children younger than the participants in this study $(93,94)$. The brain stimulation device will be operated by experienced psychologists, neuroscientists, and research assistants trained in the application. Therefore, no serious adverse events or serious health risks for the participants of this study are expected. In the case of a serious adverse event, the participant will be excluded from the trial and the adverse event will be reported to the ethics committee of the Medical University of Vienna and to the Austrian Agency for Health and Food Safety (AGES). To protocol adverse effects, the German version of the questionnaire of sensations related to transcranial electrical stimulation will be used at the last stimulation session (accessible at: http://neurologie.uni-goettingen.de/downloads. html).

\section{Instruments}

In accordance with the complexity of the disorder, the effects of the tDCS intervention will be investigated at three different levels:

1. Psychological ratings to detect changes in ASD symptoms as well as in comorbid symptoms;

2. Neurophysiological measures to detect changes in brain responses to emotional stimuli;

3. Behavioral tests to detect changes in responses and gaze behavior.

\section{Psychological Ratings}

Clinical information via questionnaires will be collected from participants and caregivers following a multi-perspective approach. The Social Responsiveness Scale [SRS; (83)] reliably indicates the presence and severity of social impairment in ASD and correlates with real-world dysfunctional behaviors. Five subscales (social awareness, social cognition, social communication, social motivation, restricted interests and repetitive behavior) and a total score will be calculated. Additionally, various instruments targeting different aspects of ASD symptoms [Autism Treatment Evaluation ChecklistATEC (95); Social Communication Questionnaire-SCQ (96)] will be used for pre-, post-, and follow-up assessments. 


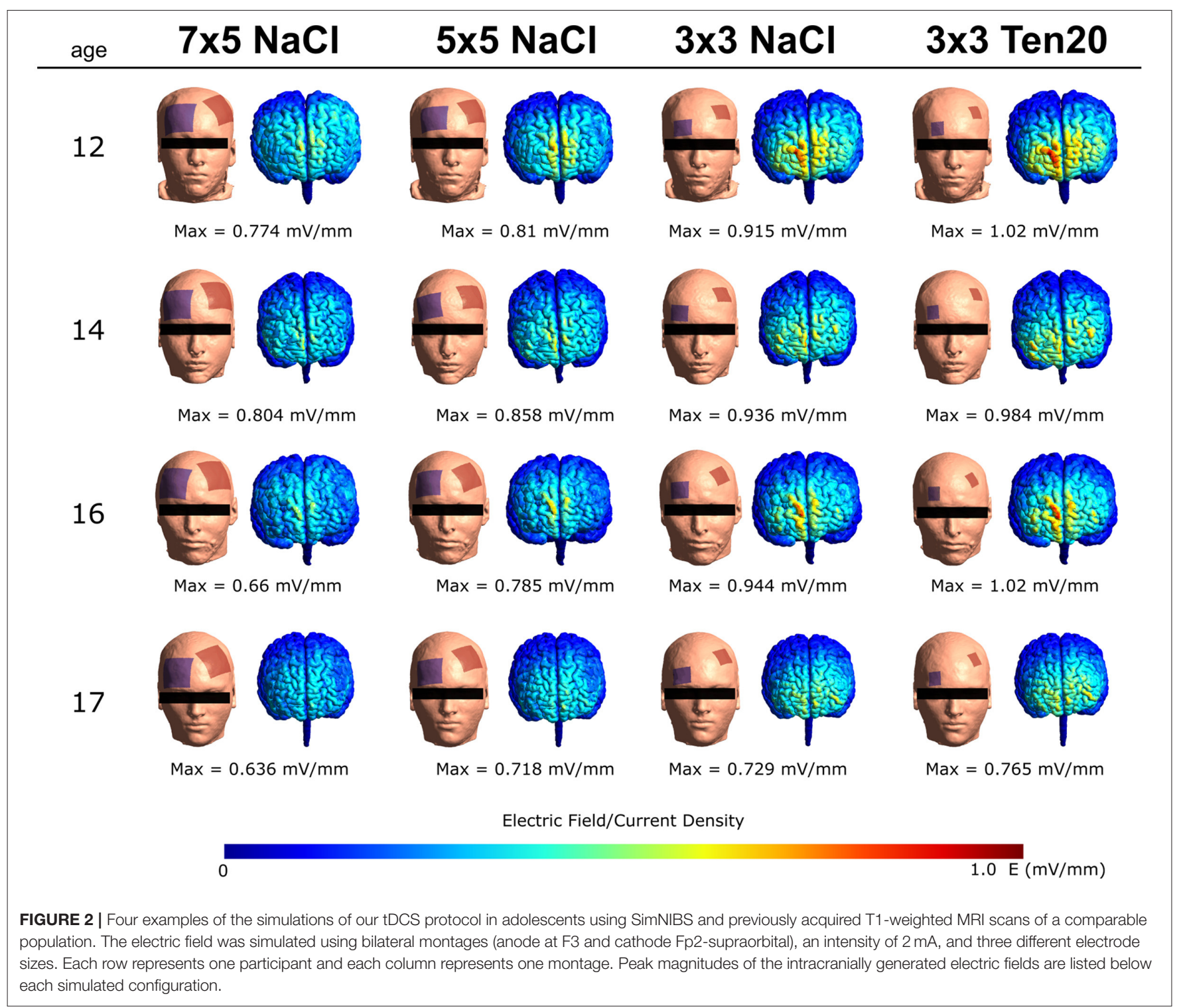

Furthermore, affective and cognitive components of empathy and emotion regulation abilities will be measured via selfreports [Emotion Regulation Questionnaire-ERQ (97); Index of Empathy for Children and Adolescents-IECA (98); Basic Empathy Scale-BES (99)] and parental questionnaires [Griffith Empathy Measure-GEM (100); Emotion Regulation Checklist-ERC (101)]. For subgroup stratification and the investigation of comorbid symptoms of ASD such as attention deficit, anxiety, aggression, and depression, the Diagnostic System for Mental Disorders in Childhood and Adolescence for ADHD, Depression, Anxiety, and Conduct Disorder [DISYPS III ADHS, DEP, ANG, SSV-self- and parental rating versions; (102)] will be used.

\section{Behavioral Tests}

Frankfurter test and training for recognizing facial affect (FEFA II): This computer-based program was developed to train and reliably test the recognition of facial affect in individuals with high-functioning ASD (103). Participants are asked to identify the six basic emotions and neutral expressions presented in 50 black-and-white photographs of faces. The stimuli used are based on Ekman's conceptualization of basic emotions (104). Correct classification and reaction times are measured.

Movie for the assessment of social cognition (MASC): The German version of the MASC (105) is a reliable and sensitive naturalistic measure of social cognition and gaze behavior in adolescents with ASD (106). The MASC consists of a film showing two females and two males having a dinner party. The film lasts about $15 \mathrm{~min}$ and is paused 43 times to ask questions about the actors' emotions, thoughts, and intentions. The revised MASC score is a measure of the degree of social cognition adopted for adolescents and will be calculated from the correct responses (106). Additionally, eye-tracking data of the participants' gaze behavior will be recorded during the 
presentation of the movie using the Tobii Pro eye-tracker (Tobii Group, Danderyd, Schweden) and Tobii Studio 3.4.5 (107).

Emotion recognition task (ERT): This self-developed task uses videos of faces and social scenes depicting different emotional states to investigate emotion recognition skills. The task involves three parts (see Figure 3 for a graphical illustration) addressing different emotion recognition competencies: (a) shows videos of one person expressing a basic or complex emotion; (b) is more challenging and presents a more naturalistic scenario in which two or more people engage in an emotional and dynamic social scene; (c) consists of morphing videos (displaying a face transitioning from a neutral expression to a basic emotion) and participants will be instructed to interrupt the morphing process as soon as they recognize the displayed emotion. Afterwards, participants will be asked to classify the emotion that was displayed in the video. The emotional stimuli represent all age groups and genders equally and are taken from validated databases. Parts (a) and (b) use stimuli form the EU Emotion Stimuli Set $(108,109)$, while part (c) uses stimuli from the FACES Database $(110,111)$. This task was implemented in Python (version 3.6.7) using the PyQt (version 5.15.2) graphics library. The ERT will be employed in pre- and post-measurements to examine changes in correct classifications and response times and to investigate pre-post changes in gaze behavior using the Tobii Pro eye-tracker (Tobii Group, Danderyd, Schweden).
Pre-stimulation task: Prior to each stimulation session, the participants will be measured on accuracy of performance and response time on the ERT. This pre-stimulation task without tDCS functions as a reference to compare with the intra-stimulation task, which is presented during tDCS. This comparison will provide information about the acute effects of tDCS on emotion recognition abilities.

Intra-stimulation training: During the $20 \mathrm{~min}$ of active or sham tDCS, all participants will undergo a structured training that aims to further stimulate the engagement of the targeted circuits during the active and sham tDCS sessions. At the first 5 min of the stimulation, the child-friendly movie Inside Out (112), which focuses on emotions and was developed with scientific consultants studying emotions, will be presented. The movie will be interrupted various times to ask questions about the mental state and emotions of the characters. Next, the ERT will be completed by the participants to further stimulate the engagement of the targeted circuits. Afterwards, the next part of the movie, again interrupted with questions, will be presented. This approach will ensure that all participants will be dealing with the same material and therefore are assumed to engage similar brain regions during the stimulation. Furthermore, this repeated examination of emotion recognition performance with the ERT will provide important information about learning curves and session-by-session changes, which may reveal insights into the optimal number of stimulation sessions.

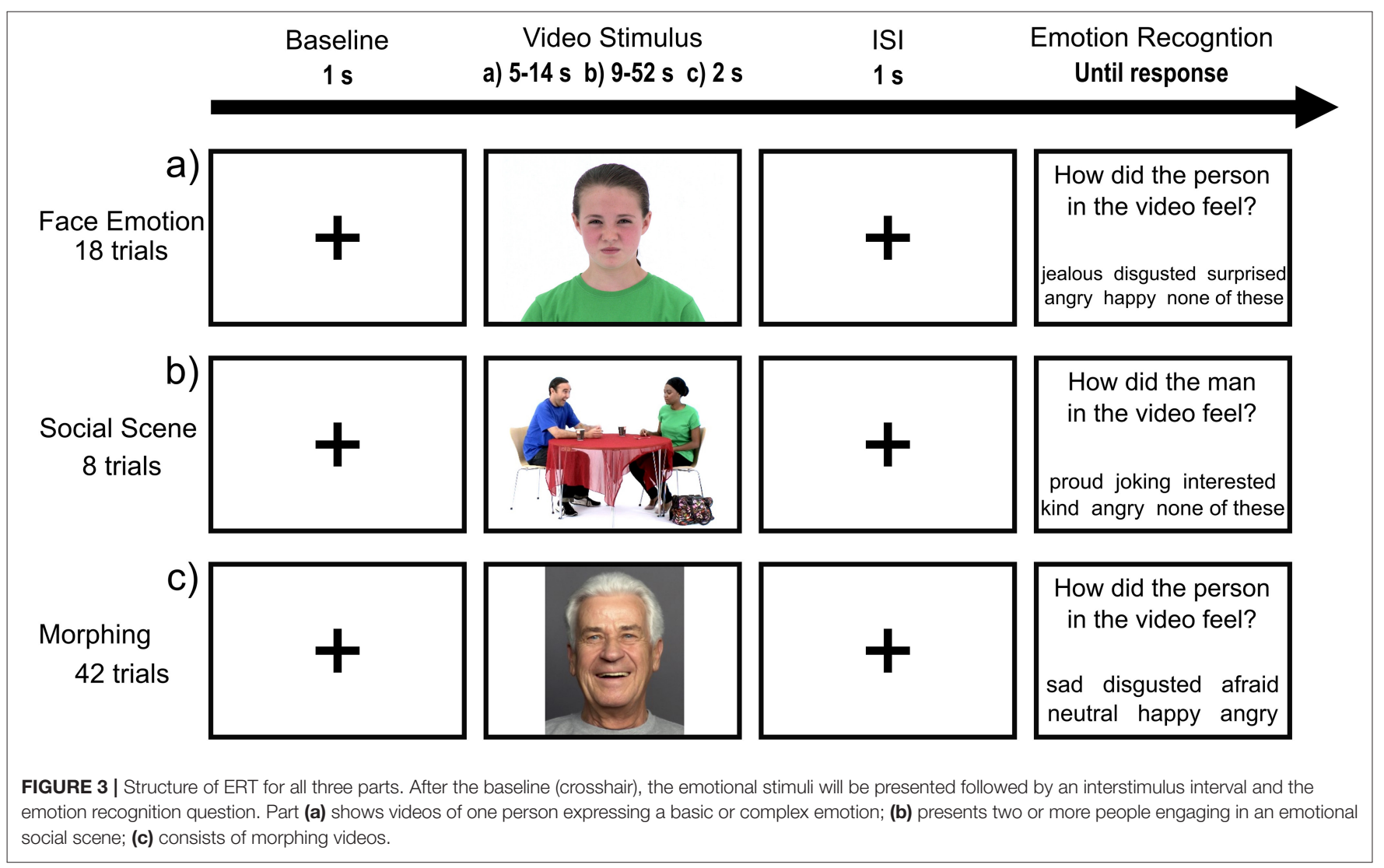




\section{Neurophysiological Measures}

EEG data acquisition: EEG data will be collected from 19 cortical sites (Fp1, Fp2, F3, F4, F7, F8, Fz, FCz, C3, $\mathrm{C} 4, \mathrm{Cz}, \mathrm{T} 5, \mathrm{~T} 6, \mathrm{P} 3, \mathrm{P} 4, \mathrm{Pz}, \mathrm{O} 1, \mathrm{O} 2$, and $\mathrm{Oz}$ ) positioned according to the international 10-20 system using $\mathrm{Ag} / \mathrm{AgCl}$ electrodes and the Thera Prax Q-EEG System (NeuroConn, Illmenau, Germany). Electrode-skin impedance will be kept below $3 \mathrm{k} \Omega$.

Resting-state EEG: Neural oscillations will be recorded in eight 1-min trials, four with eyes-closed (C) and four with eyes-open $(\mathrm{O})$. A guideline-based counterbalanced order (COCO-pause-OCOC) will be used considering disorder-specific characteristics such as a discomfort with longer eyes-closed intervals and minimizing the risk of participants falling asleep in the eyes-closed condition $(113,114)$.

MRI data acquisition: Functional and structural whole-brain imaging will be conducted using a 3-T Siemens MAGNETOM Prisma MR Scanner (Siemens, Erlangen, Germany) equipped with a 64-channel head coil.

Resting-state fMRI: RS data will be acquired for 7 min using an echo-planar imaging sequence with the following parameters: $\mathrm{TE} / \mathrm{TR}=35 / 728 \mathrm{~ms}$, field of view $($ FoV $)=192 \times 192 \times 144 \mathrm{~mm}$, matrix size $=96 \times 96,72$ slices, multiband factor $=8$, resulting in an isotropic voxel size of $2 \mathrm{~mm}$, flip angle $=55^{\circ}$ (optimized Ernst angle), and bandwidth $=3,365 \mathrm{~Hz} / \mathrm{Px}$ [sequence optimized according to (115)]. To reduce head motion and participant drowsiness, the movie Inscapes (116) will be shown during resting-state recordings. This non-social movie features abstract shapes and was developed for the use with children and clinical populations to increase compliance while minimizing cognitive demand (116).

ToM-task: frith-happé animations (FHA): To investigate changes in the ability to infer people's thoughts and feelings, a validated ToM-task, the FHA, will be used (117-119). Participants will be instructed to categorize 12 video clips depicting two animated triangles as showing either no interaction/random movements, physical interaction/goaldirected behavior, or emotional interaction/ToM after each video. Additionally, after the four ToM trials only, they need to state how each of the triangles felt at the end of the video using visual analog scales (VAS). VAS are used instead of the original good/neutral/bad decision to allow for more finegrained inferences. For each decision (i.e., the video category and emotional state of each triangle), subjects are given $5 \mathrm{~s}$, before the paradigm continues, even when no answer was given. One trial contains up to three baseline (BL) periods: (1) Before the videos, BLs are uniformly jittered between 7 and 13 s. (2) Before the category choice, the BL is between 2 and $4 \mathrm{~s}$. (3) In case a ToM video was shown, the BL before the VAS is $6 \mathrm{~s}$ minus the duration for 2 .

Emotion recognition task: Parts (a) and (c) of the ERT (see Figure 3) will be presented during MRI using a jittered and randomized baseline duration between (a) 9-15 s and (c) 5$10 \mathrm{~s}$. Imaging is conducted using the same parameters as for the resting-state recordings.

Structural MRI: These measures will be performed to exclude previously unknown alterations in brain anatomy using the following parameters: T1: TE/TR/TI $=2.29 / 2,300 / 900 \mathrm{~ms}, \mathrm{FoV}$ $=165.44 \times 240 \times 240 \mathrm{~mm}$, matrix size $=256 \times 256,176$ slices, $0.94 \times 0.94 \times 0.94 \mathrm{~mm}$ voxel size (rounded), flip angle $=8^{\circ}$, bandwidth $=200 \mathrm{~Hz} / \mathrm{Px}$; T2: TE $/ \mathrm{TR}=408 / 3,200 \mathrm{~ms}$, FoV $=$ $172.8 \times 230 \times 230 \mathrm{~mm}$, matrix size $=256 \times 256,192$ slices, $0.9 \times$ $0.9 \times 0.9 \mathrm{~mm}$ voxel size (rounded), flip angle $=120^{\circ}$, bandwidth $=725 \mathrm{~Hz} /$ Px. During the structural scans, cartoons will be shown to the participants.

\section{Outcomes}

The primary outcome will be a reduction in ASD symptoms from baseline in the experimental group compared to the sham group. ASD symptoms will be quantified by the raw score of the German version of the SRS (83) assessed by the primary caregiver.

The secondary outcomes will be increased social cognition and emotion recognition quantified by the raw scores of the MASC (105) as well as correct classifications in the ERT and the FEFA 2 (120). Regarding gaze behavior, longer fixation duration on the eyes and increased pupil dilation will be the outcomes on the MASC and ERT. Outcomes on participants and caregiver ratings will be a decrease in ASD symptoms measured with the ATEC (95) and SCQ (96) and an increase in empathy and emotion regulation abilities measured with the ERQ (97), IECA (98), BES (99), GEM (100), and ERC (101). Neurophysiological activity will be measured at baseline and after the intervention using resting-state EEG and fMRI to measure changes in functional connectivity and electrical activity in the brain. We expect an increased resting-state alphapower, a decrease in the other frequency bands, and an increased connectivity within the ToM network and DMN. An increased regional activation in key areas of the $\mathrm{SBN}$ will be the outcomes during the FHA and ERT.

The exploratory outcomes will include participant and caregiver ratings on comorbid symptoms of ASD using the DISYPS III (102). The brain activation in regions involved in emotion recognition processes and cognitive empathy during emotion recognition with the ERT during fMRI will also be examined exploratorily.

\section{Statistical Analysis}

For the statistical analyses, repeated measures analysis of variance (ANOVA) and hierarchical linear models (HLMs) will be used. A $4 \times 2$ mixed ANOVA (primary outcome as dependent variable) with Time (pre vs. post vs. follow-up 1 vs. follow-up 2 ) as the within-subjects factor and Group (experimental vs. control group) as the between-subject factor will be conducted to investigate an interaction between time and group. In order to test specific effects, post-hoc tests will be employed. A HLM will be formulated to investigate time-dependent changes and group differences in task performance across stimulation sessions. A $p$ $<0.05$ will be considered statistically significant. Analysis will be conducted in $R$ (121).

For the eye-tracking data, analysis of fixation duration and pupil dilation will be done in Tobii Studio 3.4 .5 (107) following the preprocessing pipeline of other studies using eye-tracking to investigate emotion recognition and social cognition in adolescents with ASD [for the ERT (17) and for the MASC 
(106)]. These results in a fixation duration on the specified area of interest (AOI) and a measure of average pupil dilation per video. Further analysis regarding pre-post comparisons of AOIs and pupil dilation will be done in $R(121)$ using linear models.

For the EEG data, we will employ the MNE library (122) written in Python (123) to execute data pre-processing, segmentation, and frequency and connectivity analyses. The raw EEG data of each participant will be segmented into epochs of $2 \mathrm{~s}$. A multi-taper method with adaptive weights will be applied to each epoch to obtain power spectral density (PSD) values in each frequency band of interest. Frequency bands of interest will be delta $(0.5-4 \mathrm{~Hz})$, theta $(4-8 \mathrm{~Hz})$, and alpha $(8-12 \mathrm{~Hz})$. Subsequently, PSD values in each frequency band will be averaged across epochs separately for each participant, measurement occasion, and experimental condition.

Basic fMRI processing will be conducted according to (124) using Statistical Parametric Mapping [SPM; (125)]. To counteract the expected high level of in-scanner motion, PESTICA/SLOMOCO $(126,127)$ and the BrainWavelet toolbox (128) will be used for additional movement and artifact correction. Spatial normalization will be performed to a custom template created using the CerebroMatic toolbox (129) to avoid implausible deformation to match the usual standard adult brain. Subject-level analysis will be conducted using the general linear model in SPM. The FHA task will be modeled according to $(118,130)$. The ERTs will be modeled as block designs with a single condition. For the morphing variant, the reaction times will be included as a parametric modulator to uncover the possible influence of the subjective strength of the perceived emotion. The RS data will be analyzed by means of seedbased functional connectivity. Since the ERTs constitute newly implemented paradigms, interesting regions of their baseline activation will be used as seeds here. Nuisance regressors for the linear models will be derived via the CompCor (131) and Friston-24 (132) approaches with an additional bandpass applied to the RS data. Group-level analyses of fMRI data will be conducted using the Flexible Factorial module in SPM. The time-by-treatment interaction effects will be tested at $p$ $<0.05$ family-wise error corrected at the peak level and with a primary threshold of $p<0.001$ uncorrected at the cluster level.

\section{DISCUSSION}

This study protocol presents the design of an RCT investigating the therapeutic effects of repeated sessions of anodal tDCS over the left DLPFC using a combined approach of EEG, fMRI, and eye-tracking data as well as clinically relevant scores from participants and caregivers. Therefore, the results of this study will elucidate the changeability of aberrant activity through neurostimulation on multiple levels.

An important determinant of stimulation effectiveness is the placement and size of the electrodes $(133,134)$. Accordingly, and in contrast to previous tDCS studies in children and adolescents with ASD, our study utilizes a parameter configuration based on computational modeling using MRI scans from adolescents with ASD for the simulations.

Another contrast to previous investigations is the use of an intra-stimulation training aiming specifically at improving social cognition and emotion recognition. The training is designed to not only motivate the participants and standardize what they are doing during the stimulation, but also to evoke activity in the target regions of the stimulation. To account for different levels of skills among the participants and to increase ecological validity, the task involves emotion recognition at different levels of difficulty using basic and complex emotions that will be presented isolated or in a dynamic social scene. Moreover, the repeated examination of emotion recognition performance will provide important information about learning curves and session-bysession changes. This may guide future projects in deciding about the ideal number of stimulation sessions, as studies investigating the cumulative effects of tDCS over several days are sparse. Furthermore, there is not much evidence available about the long-term effects of this treatment method. By including two follow-up measures, this study will provide information about the persistence of treatment effects regarding the clinical symptomatology up to 6 months after the end of the intervention.

Within this project, it will also be monitored how the participants react to the stimulation using the questionnaire of sensations related to transcranial electrical stimulation. Even though the safety of tDCS in pediatric populations has been demonstrated repeatedly (92), information about how this patient group perceives and tolerates the mild adverse events of tDCS seems warranted. Individuals with ASD often suffer from sensory hypersensitivity (135) and may thus respond differently to the stimulation.

In this trial, a standard bipolar tDCS montage will be used with the anode placed over the DLPFC targeting the MPFC. However, other montages or stimulation methods such as multielectrode tDCS or repetitive transcranial magnetic stimulation (rTMS) are also of interest for this population. Here, this established bipolar direct current protocol was chosen as it has milder side effects, has no history of reported serious adverse effects, and is noiseless compared to rTMS (91, 92, 136, 137). Therefore, it might be better tolerated in individuals with ASD, and participants will not be distracted from the intra-stimulation training by potentially painful sensations or sound. Regarding the usage of tDCS as a clinical treatment, a bipolar tDCS has the advantage of being more affordable, portable, and easy to administer, and it opens the possibility for home use in the future. A comparison of the effects of different stimulation protocols as well as stimulation sites is an essential element for future studies.

During the intervention, participants will have daily contact with the study team and undergo the intra-stimulation training. Although these factors could have a beneficial effect on ASD symptoms and emotion recognition skills, the double-blind design and randomization to either active or sham tDCS treatment should mitigate this potential bias.

In conclusion, children and adolescents with ASD are in need of an effective treatment, and modulating brain activity could be a first step toward a new efficient intervention. This 
neurophysiologically based approach benefits from being noninvasive, being easy to administer, and having only mild and transient side effects $(92,138)$. TDCS further aims to overcome shortcomings of traditional interventions, such as often long and expensive treatment periods (5). Taken together, this study will provide information about the efficacy of tDCS and the potential to establish it as an affordable alternative or additive treatment for individuals with ASD in the long run.

\section{TRIAL STATUS}

The described trial is ongoing, and recruitment commenced in July 2019. Recruitment and interventions had to be paused due to COVID-19 restrictions from March 13, 2020 to June 15, 2020. The data collection will continue until 20 participants completed all 10 intervention sessions and the corresponding pre- and postmeasurements. Follow-ups will be conducted 1 and 6 months after the stimulation sessions to investigative long-lasting effects.

\section{ETHICS STATEMENT}

The study was approved by the ethics committee of the Medical University of Vienna and the Austrian Agency for Health and Food Safety (AGES) and will be conducted according to the Declaration of Helsinki. Both participants and caregivers receive information sheets and consent forms about the study to take home. Participants and caregivers must agree to take part in the study and return their signed informed consent forms, before

\section{REFERENCES}

1. Maenner MJ, Shaw KA, Baio J, Washington A, Patrick M, DiRienzo $\mathrm{M}$, et al. Prevalence of autism spectrum disorder among children aged 8 Years - Autism and developmental disabilities monitoring network, 11 Sites, United States, 2016. MMWR Surveill Summar. (2020) 69:1-12. doi: 10.15585/mmwr.ss6904al

2. Loomes R, Hull L, Mandy WPL. What is the male-to-female ratio in autism spectrum disorder? A systematic review and meta-analysis. J Am Acad Child Adolesc Psychiatry. (2017) 56:466-74. doi: 10.1016/j.jaac.2017.03.013

3. WHO (2016). Internationale Klassifikation psychischer Störungen: ICD-10. Göttingen: Hogrefe.

4. Medavarapu, S., Marella, L. L., Sangem, A., and Kairam, R. (2019). Where is the evidence? A narrative literature review of the treatment modalities for autism spectrum disorders. Cureus. 11:e3901. doi: 10.7759/cureus.3901

5. DeFilippis M, Wagner KD. Treatment of autism spectrum disorder in children and adolescents. Psychopharmacol Bull. (2016) 46:18-41.

6. Fuentes J, Hervás A, Howlin P. ESCAP practice guidance for autism: a summary of evidence-based recommendations for diagnosis and treatment. Eur Child Adolesc Psychiatry. (2020) 30:961-84. doi: 10.1007/s00787-020-01587-4

7. Sandbank M, Bottema-Beutel K, Crowley S, Cassidy M, Dunham K, Feldmann JI, et al. Project AIM: autism intervention metaanalysis for studies of young children. Psychol Bull. (2020) 146:1-29. doi: 10.1037/bul0000215

8. Howlin P, Magiati I. Autism spectrum disorder: outcomes in adulthood. Curr Opin Psychiatry. (2017) 30:69-76. doi: 10.1097/YCO.0000000000000308

9. Howlin P, Moss P. Adults with autism spectrum disorders. Can J Psychiatry. (2012) 57:275-83. doi: 10.1177/070674371205700502

10. Barrera ME, Maurer D. The perception of facial expressions by the threemonth-old. Child Dev. (1981) 52:203-6. doi: 10.2307/1129231 being included in the study. Consent can be withdrawn by the participants or caregivers at any time without any effect on their standard clinical treatment.

\section{AUTHOR CONTRIBUTIONS}

KP, LK, LP, and PP designed the trial. KP and SR developed, programmed, and piloted the ERT paradigm. GA, KP, and LK designed the stimulation model and defined the stimulation parameters. MK, RL, SR, and KP planned the data analysis. KP and LK coordinate the recruitment of the participants. KP and $\mathrm{MK}$ are responsible for the data collection during the study. KP, SR, GA, MK, RL, PP, LP, and LK wrote, edited, and revised the paper. All authors approved the final manuscript.

\section{FUNDING}

KP, SR, GA, MK, and LK are partly supported by the Austrian Science Fund (FWF): KLI600B27. SR was supported by the German Research Foundation (DFG): GRK2277.

\section{ACKNOWLEDGMENTS}

The authors would like to acknowledge Franz Benninger, Kamer Doganay, Nina Ebner, Mercedes Huscsava, Susanne Ohmann, Julia Philipp, Thomas Straß, Christine Vesely, and Sonja Werneck-Rohrer (in alphabetical order) for assisting in the recruiting process and IT.
11. Meinhardt-Injac B, Kurbel D, and Meinhardt G. The coupling between face and emotion recognition from early adolescence to young adulthood. Cogn. Dev. (2020) 53:100851. doi: 10.1016/j.cogdev.2020.100851

12. Rueda P, Fernández-Berrocal P, Baron-Cohen S. Dissociation between cognitive and affective empathy in youth with Asperger Syndrome. Eur J Dev Psychol. (2015) 12:85-98. doi: 10.1080/17405629.2014.950221

13. Uljarevic M, Hamilton A. Recognition of emotions in autism: a formal meta-analysis. J Aut. (2013) 43:1517-26. doi: 10.1007/s10803-012-1695-5

14. Sivaratnam CS, Newman LK, Tonge BJ, Rinehart NJ. Attachment and emotion processing in children with autism spectrum attachment and emotion processing in children with autism spectrum disorders : neurobiological, neuroendocrine, and neurocognitive considerations. Rev J Autism Dev Disord. (2015) 2:222-42. doi: 10.1007/s40489-015-0048-7

15. Von Dem Hagen EAH, Stoyanova RS, Rowe JB, Baron-Cohen S, Calder AJ. Direct gaze elicits atypical activation of the theory-of-mind network in Autism spectrum conditions. Cereb Cortex. (2014) 24:148592. doi: 10.1093/cercor/bht003

16. Papagiannopoulou EA, Chitty KM, Hermens DF, Hickie IB, Papagiannopoulou EA, Chitty KM, et al. A systematic review and meta-analysis of eye-tracking studies in children with autism spectrum disorders. Soc Neurosci. (2014) 9:37-41. doi: 10.1080/17470919.2014.9 34966

17. Reisinger DL, Shaffer RC, Horn PS, Hong MP, Pedapati EV, Dominick KC, et al. Atypical social attention and emotional face processing in autism spectrum disorder: insights from face scanning and pupillometry. Front Integr Neurosci. (2020) 13:76. doi: 10.3389/fnint.2019.00076

18. Blakemore SJ. The social brain in adolescence. Nat Rev Neurosci. (2008) 9:267-77. doi: 10.1038/nrn2353

19. Mills KL, Lalonde F, Clasen LS, Giedd JN, Blakemore SJ. Developmental changes in the structure of the social brain in late childhood and adolescence. Soc Cogn Affect Neurosci. (2014) 9:123-31. doi: 10.1093/scan/nss113 
20. Sato $\mathrm{W}$, Uono S. The atypical social brain network in autism: advances in structural and functional MRI studies. Curr Opin Neurol. (2019) 32:61721. doi: 10.1097/WCO.0000000000000713

21. D’Albis MA, Guevara P, Guevara M, Laidi C, Boisgontier J, Sarrazin S, et al. Local structural connectivity is associated with social cognition in autism spectrum disorder. Brain. (2018) 141:3472-81. doi: 10.1093/brain/awy275

22. Pereira AM, Campos BM, Coan AC, Pegoraro LF, de Rezende TJR, Obeso I, et al. Differences in cortical structure and functional MRI connectivity in high functioning autism. Front. Neurol. (2018) 9:539. doi: 10.3389/fneur.2018.00539

23. Sato W, Uono S, Kochiyama T, Yoshimura S, Sawada R, Kubota $\mathrm{Y}$, et al. Structural correlates of reading the mind in the eyes in autism spectrum disorder. Front Hum Neurosci. (2017) 11:361. doi: 10.3389/fnhum.2017.00361

24. Yang X, Si T, Gong Q, Qiu L, Jia Z, Zhou M, et al. Brain gray matter alterations and associated demographic profiles in adults with autism spectrum disorder: a meta-analysis of voxel-based morphometry studies. Austr N Z J Psychiatry. (2016) 50:741-53. doi: 10.1177/0004867415623858

25. Müller R-A, Fishman I. Brain connectivity and neuroimaging of social networks in autism. Trends Cogn Sci. (2018) 22:110316. doi: 10.1016/j.tics.2018.09.008

26. Ciaramidaro A, Bölte S, Schlitt S, Hainz D, Poustka F, Weber B, et al. Transdiagnostic deviant facial recognition for implicit negative emotion in autism and schizophrenia. Eur Neuropsychopharmacol. (2018) 28:26475. doi: 10.1016/j.euroneuro.2017.12.005

27. Carrington SJ, Bailey AJ. Are there theory of mind regions in the brain? A review of the neuroimaging literature. Hum Brain Mapp. (2009) 30:231335. doi: 10.1002/hbm.20671

28. Doyle-Thomas KAR, Lee W, Foster NEV, Tryfon A, Ouimet T, Hyde KL, et al. Atypical functional brain connectivity during rest in autism spectrum disorders. Ann Neurol. (2015) 77:866-76. doi: 10.1002/ana.24391

29. Yerys BE, Gordon EM, Abrams DN, Satterthwaite TD, Weinblatt R, Jankowski KF, et al. Default mode network segregation and social deficits in autism spectrum disorder: evidence from non-medicated children DMN in children with ASD. NeuroImage. (2015) 9:22332. doi: 10.1016/j.nicl.2015.07.018

30. Buckner RL, DiNicola LM. The brain's default network: updated anatomy, physiology and evolving insights. Nat Rev Neurosci. (2019) 20:593608. doi: 10.1038/s41583-019-0212-7

31. Minshew NJ, Keller TA. The nature of brain dysfunction in autism: functional brain imaging studies. Curr Opin Neurol. (2010) 23:12430. doi: 10.1097/WCO.0b013e32833782d4

32. Kleinhans NM, Richards T, Sterling L, Stegbauer KC, Mahurin R, Johnson LC, et al. Abnormal functional connectivity in autism spectrum disorders during face processing. Brain. (2008). 131(Pt 1):1000-12. doi: 10.1093/brain/awm334

33. Washington SD, Gordon EM, Brar J, Warburton S, Sawyer AT, Wolfe A, et al. Dysmaturation of the default mode network in autism. Hum Brain Mapp. (2014) 35:1284-96. doi: 10.1002/hbm.22252

34. Odriozola P, Dajani DR, Burrows CA, Gabard-Durnam LJ, Goodman E, Baez $\mathrm{AC}$, et al. Atypical frontoamygdala functional connectivity in youth with autism. Dev Cogn Neurosci. (2019) 37:100603. doi: 10.1016/j.dcn.2018.12.001

35. Jung $\mathrm{M}, \mathrm{Tu} \mathrm{Y}$, Lang $\mathrm{CA}$, Ortiz A, Park J, Jorgenson $\mathrm{K}$, et al. Decreased structural connectivity and resting-state brain activity in the lateral occipital cortex is associated with social communication deficits in boys with autism spectrum disorder. Neuroimage. (2019) 190:20512. doi: 10.1016/j.neuroimage.2017.09.031

36. Wang J, Barstein J, Ethridge LE, Mosconi MW, Takarae Y, Sweeney JA. Resting state EEG abnormalities in autism spectrum disorders. J Neurodev Disord. (2013) 5:24. doi: 10.1186/1866-1955-5-24

37. Zhou T, Kang J, Cong F, Li DX. Early childhood developmental functional connectivity of autistic brains with non-negative matrix factorization. NeuroImage. (2020) 26:102251. doi: 10.1016/j.nicl.2020.102251

38. Mash LE, Keehn B, Linke AC, Liu TT, Helm JL, Haist F, et al. Atypical relationships between spontaneous EEG and fMRI activity in Autism. Brain Connect. (2020) 10:18-28. doi: 10.1089/brain.2019.0693

39. Brunoni AR, Nitsche MA, Bolognini N, Bikson M, Wagner T, Merabet $\mathrm{L}$, et al. Clinical research with transcranial direct current stimulation
(tDCS): challenges and future directions. Brain Stimul. (2012) 5:17595. doi: 10.1016/j.brs.2011.03.002

40. Nitsche MA, Paulus W. Excitability changes induced in the human motor cortex by weak transcranial direct current stimulation. J Physiol. (2000) 633-9. doi: 10.1111/j.1469-7793.2000.t01-1-00633.x

41. Antal A, Terney D, Poreisz C, Paulus W. Towards unravelling task-related modulations of neuroplastic changes induced in the human motor cortex. Eur J Neurosci. (2007) 26:2687-91. doi: 10.1111/j.1460-9568.2007.05896.x

42. Stagg CJ, Antal A, Nitsche MA. Physiology of transcranial direct current stimulation. JECT. (2018) 34:144-52. doi: 10.1097/YCT.0000000000000510

43. Krause B, Cohen Kadosh R. Can transcranial electrical stimulation improve learning difficulties in atypical brain development? A future possibility for cognitive training. Dev Cogn Neurosci. (2013) 6:17694. doi: 10.1016/j.den.2013.04.001

44. Nitsche M, Liebetanz D, Lang N, Antal A, Tergau F, Paulus W, et al. Safety criteria for transcranial direct current stimulation (tDCS) in humans [1] (multiple letters). Clin Neurophysiol. (2003) 114:22203. doi: 10.1016/S1388-2457(03)00235-9

45. Palm U, Segmiller FM, Epple AN, Freisleder F-J, Koutsouleris N, SchulteKörne G, et al. Transcranial direct current stimulation in children and adolescents: a comprehensive review. J Neural Transm. (2016) 123:121934. doi: 10.1007/s00702-016-1572-z

46. Vecchio F, Di Iorio R, Miraglia F, Granata G, Romanello R, Bramanti P, et al. Transcranial direct current stimulation generates a transient increase of small-world in brain connectivity: an EEG graph theoretical analysis. Exp Brain Res. (2018) 236:1117-27. doi: 10.1007/s00221-018-5200-z

47. Balconi M, Vitaloni S. The tDCS effect on alpha brain oscillation for correct vs. incorrect object use the contribution of the left DLPFC. Neurosci Lett. (2012) 517:25-9. doi: 10.1016/j.neulet.2012.04.010

48. Mangia AL, Pirini M, Cappello A. Transcranial direct current stimulation and power spectral parameters: a tDCS/EEG co-registration study. Front Hum Neurosci. (2014) 8:601. doi: 10.3389/fnhum.2014.00601

49. Spitoni GF, Cimmino RL, Bozzacchi C, Pizzamiglio L, Di Russo F. Modulation of spontaneous alpha brain rhythms using low-intensity transcranial direct-current stimulation. Front Hum Neurosci. (2013) 7:529. doi: 10.3389/fnhum.2013.00529

50. Antonenko XD, Schubert F, Bohm XF, Ittermann B, Aydin S, Hayek $\mathrm{D}$, et al. tDCS-Induced modulation of GABA levels and resting-state functional connectivity in older adults. J. Neurosci. (2017) 37:406573. doi: 10.1523/JNEUROSCI.0079-17.2017

51. Keeser D, Meindl T, Bor J, Palm U, Pogarell O, Mulert C, et al. Prefrontal transcranial direct current stimulation changes connectivity of resting-state networks during fMRI. J Neurosci. (2011) 31:1528493. doi: 10.1523/JNEUROSCI.0542-11.2011

52. Neeb L, Bayer A, Bayer K, Farmer A, Fiebach JB, Siegmund B, et al. Transcranial direct current stimulation in inflammatory bowel disease patients modifies resting-state functional connectivity: a RCT. Brain Stimul. (2019) 12:978-80. doi: 10.1016/j.brs.2019.03.001

53. Weber MJ, Messing SB, Rao H, Detre JA, Thompson-Schill SL. Prefrontal transcranial direct current stimulation alters activation and connectivity in cortical and subcortical reward systems: a tDCS-fMRI study. Hum Brain Mapp. (2014) 35:3673-86. doi: 10.1002/hbm.22429

54. Deng Z, De Luber B, Balderston NL, Velez Afanador M, Noh MM, Thomas J, et al. Device-based modulation of neurocircuits as a therapeutic for psychiatric disorders. Annu Rev Pharmacol Toxicol. (2020) 60:591-614. doi: 10.1146/annurev-pharmtox-010919023253

55. Ke Y, Wang N, Du J, Kong L, Liu S, Xu M, et al. The effects of transcranial direct current stimulation (tDCS) on working memory training in healthy young adults. Front Hum Neurosci. (2019) 13:19. doi: 10.3389/fnhum.2019.00019

56. Martin DM, Teng JZ, Lo TY, Alonzo A, Goh T, Iacoviello BM, et al. Clinical pilot study of transcranial direct current stimulation combined with Cognitive Emotional Training for medication resistant depression. J Affect Disord. (2018) 232:89-95. doi: 10.1016/j.jad.2018.02.021

57. Chan MMY, Han YMY. (2020). Effects of transcranial direct current stimulation (tdcs) in the normalization of brain activation in patients with neuropsychiatric disorders: a systematic review of 
neurophysiological and neuroimaging studies. Neural Plast. (2020) 2020:8854412. doi: 10.1155/2020/8854412

58. Adeyemo BO, Simis M, Macea DD, Fregni F. Systematic review of parameters of stimulation, clinical trial design characteristics, and motor outcomes in non-invasive brain stimulation in stroke. Front Psychiatry. (2012) 3:88. doi: 10.3389/fpsyt.2012.00088

59. Biou E, Cassoudesalle H, Cogné M, Sibon I, De Gabory I, Dehail $\mathrm{P}$, et al. Transcranial direct current stimulation in post-stroke aphasia rehabilitation: a systematic review. Ann Phys Rehabil Med. (2019) 62:10421. doi: 10.1016/j.rehab.2019.01.003

60. Dondé C, Amad A, Nieto I, Brunoni AR, Neufeld NH, Bellivier F, et al. Transcranial direct-current stimulation (tDCS) for bipolar depression: a systematic review and meta-analysis. Prog NeuroPsychopharmacol Biol Psychiatry. (2017) 78:123-31. doi: 10.1016/j.pnpbp.201 7.05.021

61. Kostova R, Cecere R, Thut G, Uhlhaas PJ. Targeting cognition in schizophrenia through transcranial direct current stimulation: a systematic review and perspective. Schizophr Res. (2020) 220:300-10. doi: 10.1016/j.schres.2020.03.002

62. Kenney-Jung DL, Blacker CJ, Camsari DD, Lee JC, Lewis CP. Transcranial direct current stimulation. Child Adolesc Psychiatr Clin N Am. (2019) 28:5360. doi: 10.1016/j.chc.2018.07.008

63. Muszkat D, Polanczyk GV, Dias TGC, Brunoni AR. Transcranial direct current stimulation in child and adolescent psychiatry. J Child Adolesc Psychopharmacol. (2016) 26:590-7. doi: 10.1089/cap.2015.0172

64. Salehinejad MA, Wischnewski M, Nejati V, Vicario CM, Nitsche MA. Transcranial direct current stimulation in attention-deficit hyperactivity disorder: a meta-analysis of neuropsychological deficits. PLoS ONE. (2019) 14:e221613. doi: 10.1371/journal.pone.0221613

65. Amatachaya A, Auvichayapat N, Patjanasoontorn N, Suphakunpinyo C, Ngernyam N, Aree-Uea B, et al. Effect of anodal transcranial direct current stimulation on autism: a randomized double-blind crossover trial. Behav Neurol. (2014) 2014:173073. doi: 10.1155/2014/173073

66. Auvichayapat N, Patjanasoontorn N, Phuttharak W, Suphakunpinyo C, Keeratitanont K, Tunkamnerdthai $\mathrm{O}$, et al. Brain metabolite changes after anodal transcranial direct current stimulation in autism spectrum disorder. Front Mol Neurosci. (2020) 13:70. doi: 10.3389/fnmol.2020.00070

67. Costanzo F, Menghini D, Casula L, Amendola A, Mazzone L, Valeri G, et al. Transcranial direct current stimulation treatment in an adolescent with autism and drug-resistant catatonia. Brain Stimul. (2015) 8:12335. doi: 10.1016/j.brs.2015.08.009

68. Gómez L, Vidal B, Maragoto C, Morales LM, Berrillo S, Cuesta $\mathrm{HV}$, et al. Non-invasive brain stimulation for children with autism spectrum disorders : a short-term outcome study. Behav Sci. (2017) 7:112. doi: 10.3390/bs7030063

69. Hadoush H, Alafeef M, Abdulhay E. Brain complexity in children with mild and severe autism spectrum disorders: analysis of multiscale entropy in EEG. Brain Topogr. (2019) 32:914-21. doi: 10.1007/s10548-019-00711-1

70. Hadoush H, Nazzal M, Almasri NA, Khalil H, Alafeef M. Therapeutic effects of bilateral anodal transcranial direct current stimulation on prefrontal and motor cortical areas in children with autism spectrum disorders: a pilot study. Autism Res. (2020) 13:828-36. doi: 10.1002/aur.2290

71. Hupfeld K, Ketcham C. Behavioral effects of transcranial direct current stimulation on motor and language planning in minimally verbal children with Autism Spectrum Disorder (ASD): feasibility, limitations and future directions. J Childh Dev Disord. (2016) 2:1-12. doi: 10.4172/2472-1786.100029

72. Kang J, Cai E, Han J, Tong Z, Li X, Sokhadze EM, et al. Transcranial direct current stimulation (tDCS) can modulate EEG complexity of children with autism spectrum disorder. Front Neurosci. (2018) 12:201. doi: 10.3389/fnins.2018.00201

73. Mahmoodifar E, Sotoodeh MS. Combined transcranial direct current stimulation and selective motor training enhances balance in children with autism spectrum disorder. Percept Mot Skills. (2020) 127:11325. doi: $10.1177 / 0031512519888072$

74. Schneider HD, Hopp JP. The use of the Bilingual Aphasia Test for assessment and transcranial direct current stimulation to modulate language acquisition in minimally verbal children with autism. Clin Linguist Phonet. (2011) 25:640-54. doi: 10.3109/02699206.2011.570852

75. Zhou T, Kang J, Li Z, Chen H, Li X. Transcranial direct current stimulation modulates brain functional connectivity in autism. NeuroImage. (2020) 28:102500. doi: 10.1016/j.nicl.2020.102500

76. Amatachaya A, Jensen MP, Patjanasoontorn N, Auvichayapat N, Suphakunpinyo C, Janjarasjitt S, et al. The short-term effects of transcranial direct current stimulation on electroencephalography in children with autism: A randomized crossover controlled trial. Behav Neurol. (2015) 2015:928631. doi: 10.1155/2015/928631

77. García-González S, Lugo-Marín J, Setien-Ramos I, Gisbert-Gustemps L, Arteaga-Henríquez G, Díez-Villoria E, et al. Transcranial direct current stimulation in Autism Spectrum Disorder: a systematic review and meta-analysis. Eur Neuropsychopharmacol. (2021) 48:89-109. doi: 10.1016/j.euroneuro.2021.02.017

78. Khaleghi A, Zarafshan H, Vand SR, Mohammadi MR. Effects of non-invasive neurostimulation on autism spectrum disorder: a systematic review. Clin Psychopharmacol Neurosci. (2020) 18:527-52. doi: 10.9758/cpn.2020.18.4.527

79. Caldas Osório AA, Brunoni AR. Transcranial direct current stimulation in children with autism spectrum disorder : a systematic scoping review. Dev Med Child Neurol. (2019) 61:298-304. doi: 10.1111/dmcn.14104

80. Gómez-Fernández L, Vidal-Martínez B, Maragoto-Rizo C, Morales-Chacón L, Berrillo-Batista S, Vera-Cuesta H, et al. Safety and effectiveness of noninvasive brain stimulation in autism spectrum disorder: results from a proof of concept study. Rev Mexicana Neuroci. (2018) 19:8-20.

81. van Steenburgh JJ, Varvaris M, Vannorsdall TD, Schretlen D, Gordon B. Transcranial direct current stimulation enhances functional connectivity in high-functioning individuals with autism. In: 43rd Annual Meeting of the Child-Neurology-Society. Vol. 76. Baltimore, MD (2014).

82. Erdfelder E, Faul F, Buchner A, Lang AG. Statistical power analyses using $G^{*}$ Power 3.1: tests for correlation and regression analyses. Behav Res Methods. (2009) 41:1149-60. doi: 10.3758/BRM.41.4.1149

83. Poustka F, Bölte S. Skala zur Erfassung sozial Reaktivität (SRS). Bern: Huber (2008).

84. Bölte S, Rühl D, Schmötzer G, Poustka F. Diagnostisches Interview für Autismus-Revidiert (ADI-R). Bern: Huber (2006).

85. Poustka L, Rühl D, Feineis-Matthews S, Poustka F, Hartung M, Bölte S. ADOS-2. Diagnostische Beobachtungsskala für Autistische Störungen 2. Deutschsprachige Fassung der Autism Diagnostic Observation Schedule. Mannheim: Huber (2015).

86. Saturnino GB, Siebner HR, Thielscher A, Madsen KH. Accessibility of cortical regions to focal TES: dependence on spatial position, safety, and practical constraints. Neuroimage. (2019) 203:116183. doi: 10.1016/j.neuroimage.2019.116183

87. Beam W, Borckardt JJ, Reeves ST, George MS. An efficient and accurate new method for locating the F3 position for prefrontal TMS applications. Brain Stimul. (2009) 2:50-4. doi: 10.1016/j.brs.2008.09.006

88. Ambrus GG, Al-Moyed H, Chaieb L, Sarp L, Antal A, Paulus W. The fade-in - short stimulation - fade out approach to sham tDCS - reliable at $1 \mathrm{~mA}$ for naïve and experienced subjects, but not investigators. Brain Stimul. (2012) 5:499-504. doi: 10.1016/j.brs.2011.12.001

89. Lefaucheur J-P, Antal A, Ayache SS, Benninger DH, Brunelin J, Cogiamanian F, et al. Evidence-based guidelines on the therapeutic use of transcranial direct current stimulation (tDCS). Clin Neurophysiol. (2017) 128:5692. doi: 10.1016/j.clinph.2016.10.087

90. Buchanan DM, Bogdanowicz T, Khanna N, Lockman-Dufour G, Robaey P, D'Angiulli A. Systematic review on the safety and tolerability of transcranial direct current stimulation in children and adolescents. Brain Sci. (2021) 11:1-21. doi: 10.3390/brainsci11020212

91. Krishnan C, Santos L, Peterson MD, Ehinger M. Safety of noninvasive brain stimulation in children and adolescents. Brain Stimul. (2015) 8:7687. doi: 10.1016/j.brs.2014.10.012

92. Antal A, Alekseichuk I, Bikson M, Brockmöller J, Brunoni AR, Chen R, et al. Low intensity transcranial electric stimulation: safety, ethical, legal regulatory and application guidelines. Clin Neurophysiol. (2017) 128:1774809. doi: 10.1016/j.clinph.2017.06.001 
93. Andrade AC, Magnavita GM, Allegro JVBN, Neto CEBP, de Cássia Saldanha Lucena R, Fregni F, et al. Feasibility of transcranial direct current stimulation use in children aged 5 to 12 years. J Child Neurol. (2014) 29:13605. doi: 10.1177/0883073813503710

94. Bandeira ID, Guimarães RSQ, Jagersbacher JG, Barretto TL, de Jesus-Silva JR, Santos SN, et al. Transcranial direct current stimulation in children and adolescents with attention-deficit/hyperactivity disorder (ADHD). J Child Neurol. (2016) 31:918-24. doi: 10.1177/0883073816630083

95. Accardo P, Bostwick H. Zebras in the living room: the changing faces of autism. J Pediatr. (1999) 135:533-5. doi: 10.1016/S0022-3476(99)70045-4

96. Bölte S, Poustka F. Fragebogen zur Sozialen Kommunikation - Austismus Screening (FSK). Bern: Huber (2006).

97. Abler B, Kessler H. Emotion regulation questionnaire - eine deutschsprachige fassung des ERQ von Gross und John. Diagnostica. (2009) 55:144-52. doi: 10.1026/0012-1924.55.3.144

98. Bryant BK. An index of empathy for children and adolescents. Child Dev. (1982) 53:413. doi: 10.2307/1128984

99. Heynen EJE, Van der Helm GHP, Stams GJJM, Korebrits AM. Measuring empathy in a german youth prison: a validation of the german version of the basic empathy scale (BES) in a sample of incarcerated juvenile offenders. J Forensic Psychol Pract. (2016) 16:336-46. doi: 10.1080/15228932.2016.1219217

100. Dadds MR, Hunter K, Hawes DJ, Frost ADJ, Vassallo S, Bunn $\mathrm{P}$, et al. A measure of cognitive and affective empathy in children using parent ratings. Child Psychiatry Hum Dev. (2008) 39:111-122. doi: 10.1007/s10578-007-0075-4

101. Shields A, Cicchetti D. Emotion regulation among school age children: the development and validation of a new criterion q-sort scale. Dev Psychol. (1997) 33:906-16. doi: 10.1037/0012-1649.33.6.906

102. Döpfner M, Görtz-Dorten A. DISYPS-III. Diagnostik-System für Psychische Störungen Nach ICD-10 und DSM-5 für Kinder und Jugendliche - III. Bern: Hogrefe (2017).

103. Bölte S, Feineis-Matthews S, Leber S, Dierks T, Hubl D, Poustka F. The development and evaluation of a computer-based program to test and to teach the recognition of facial affect. Int J Circump Health. (2002) 61(Suppl. 2):61-8. doi: 10.3402/ijch.v61i0.17503

104. Ekman P, Friesen WV. Constants across cultures in the face and emotion. J Pers Soc Psychol. (1971) 17:124-9. doi: 10.1037/h0030377

105. Dziobek I, Fleck S, Kalbe E, Rogers K, Hassenstab J, Brand M, et al. Introducing MASC: a movie for the assessment of social cognition. J Autism Dev Disord. (2006) 36:623-36. doi: 10.1007/s10803-006-0107-0

106. Müller N, Baumeister S, Dziobek I, Banaschewski T, Poustka L. Validation of the movie for the assessment of social cognition in adolescents with ASD: fixation duration and pupil dilation as predictors of performance. J Autism Dev Disord. (2016) 46:2831-44. doi: 10.1007/s10803-016-2828-Z

107. Tobii Pro AB. Tobii Studio (Version 3.4.5). Danderyd: Tobii Pro AB (2016).

108. O’Reilly H, Lundqvist D, Pigat D, Baron K, Fridenson S, Tal S, et al. The EU-Emotion Stimulus Set. Cambridge: Autism Research Centre; University of Cambridge (2012).

109. O'Reilly H, Pigat D, Fridenson S, Berggren S, Tal S, Golan O, et al. The EU-emotion stimulus set : a validation study. Behav Res Methods. (2016) 48:567-76. doi: 10.3758/s13428-015-0601-4

110. Ebner N, Riediger M, Lindenberger U. FACES - A database of facial expressions in young. middle-aged, and older women and men. Behav Res Methods. (2010) 42:351-62. doi: 10.3758/BRM.42.1.351

111. Holland CAC, Ebner NC, Lin T, Samanez-Larkin GR. Emotion identification across adulthood using the Dynamic FACES database of emotional expressions in younger, middle aged, and older adults. Cogn Emot. (2018) 33:245-57. doi: 10.1080/02699931.2018.1445981

112. Docter P, and Del Carmen R. Inside Out. Walt Disney Studios Motion Pictures (2015).

113. Jia $\mathrm{H}, \mathrm{Yu} \mathrm{D}$. Aberrant intrinsic brain activity in patients with autism spectrum disorder: insights from eeg microstates. Brain Topogr. (2019) 32:295-303. doi: 10.1007/s10548-018-0685-0

114. Jobert M, Wilson FJ, Ruigt GSF, Brunovsky M, Prichep LS, Drinkenburg. Guidelines for the recording and evaluation of pharmaco-EEG data in man: the international pharmaco-EEG society (IPEG). Neuropsychobiology. (2012) 66:201-20. doi: $10.1159 / 000343478$
115. Smith SM, Andersson J, Auerbach EJ, Beckmann CF, Bijsterbosch J, Douaud $\mathrm{G}$, et al. Resting-state fMRI in the human connectome project. Neuroimage. (2013) 80:144-68. doi: 10.1016/j.neuroimage.2013.05.039

116. Vanderwal T, Kelly C, Eilbott J, Mayes LC, Castellanos FX. Inscapes: a movie paradigm to improve compliance in functional magnetic resonance imaging. Neuroimage. (2015) 122:222-32. doi: 10.1016/j.neuroimage.2015.07.069

117. Abell F, Happe F, Frith U. Do triangles play tricks? Attribution of mental states to animated shapes in normal and abnormal development. J Cogn Dev. (2000) 15:1-20. doi: 10.1016/S0885-2014(00)00014-9

118. Moessnang C, Schäfer A, Bilek E, Roux P, Otto K, Baumeister S, et al. Specificity, reliability and sensitivity of social brain responses during spontaneous mentalizing. Soc Cogn Affect Neurosci. (2016) 168797. doi: 10.1093/scan/nsw098

119. White SJ, Coniston D, Rogers R, Frith U. Developing the frith-happe animations: a quick and objective test of theory of mind for adults with autism. Autism Res. (2011) 4:149-54. doi: 10.1002/aur.174

120. Bölte S, Feineis-Matthews S, Poustka F. Frankfurter Test und Training des Erkennens von fazialem Affekt (FEFA). Klinik für Psychiatrie und Psychotherapie des Kindes- und Jugendalter, Klinikum der J.W.G.Universität. (2003).

121. R Core Team. R: A Language and Environment for Statistical Computing. Vienna: R Core Team (2020).

122. Gramfort A, Luessi M, Larson E, Engemann DA, Strohmeier D, Brodbeck C, et al. MEG and EEG data analysis with MNE-Python. Front. Neurosci. (2013) 7:267. doi: 10.3389/fnins.2013.00267

123. Gramfort A, Luessi M, Larson E, Engemann D, Strohmeier D, Brodbeck C, et al. MNE software for processing MEG and EEG data. Neuroimage. (2014) 86:446-60. doi: 10.1016/j.neuroimage.2013.10.027

124. Poldrack RA, Mumford JA, Nichols TE. Handbook of Functional MRI Data Analysis. Cambridge: Cambridge University Press (2011).

125. Friston K, Ashburner J, Kiebel S, Nichols T, Penny W. (editors.). Statistical Parametric Mapping. The Analysis of Functional Brain Images. London: Academic Press (2007).

126. Beall EB, Lowe MJ. Isolating physiologic noise sources with independently determined spatial measures. Neuroimage. (2007) 37:1286-300. doi: 10.1016/j.neuroimage.2007.07.004

127. Beall EB, Lowe MJ. SimPACE: Generating simulated motion corrupted BOLD data with synthetic-navigated acquisition for the development and evaluation of SLOMOCO: a new, highly effective slicewise motion correction. Neuroimage. (2014) 101:21-34. doi: 10.1016/j.neuroimage.2014.06.038

128. Patel AX, Kundu P, Rubinov M, Jones PS, Vértes PE, Ersche $\mathrm{KD}$, et al. A wavelet method for modeling and despiking motion artifacts from resting-state fMRI time series. Neuroimage. (2014) 95:287-304. doi: 10.1016/j.neuroimage.2014.03.012

129. Wilke M, Altaye M, Holland SK, The CMIND Authorship Consortium. CerebroMatic: a versatile toolbox for spline-based MRI template creation. Front Comput Neurosci. (2017) 11:5. doi: 10.3389/fncom.2017.00005

130. Moessnang C, Baumeister S, Tillmann J, Goyard D, Charman T, Ambrosino $\mathrm{S}$, et al. Social brain activation during mentalizing in a large autism cohort: the Longitudinal European Autism Project. Mol Autism. (2020) 11:1-17. doi: 10.1186/s13229-020-0317-x

131. Behzadi Y, Restom K, Liau J, Liu TT. A component based noise correction method (CompCor) for BOLD and perfusion based fMRI. Neuroimage. (2007) 37:90-101. doi: 10.1016/j.neuroimage.2007.04.042

132. Friston KJ, Williams S, Howard R, Frackowiak RS, Turner R. Movementrelated effects in fMRI time-series. Magn Reson Med. (1996) 35:34655. doi: 10.1002/mrm.1910350312

133. Medeiros LF, de Souza ICC, Vidor LP, de Souza A, Deitos A, Volz MS, et al. Neurobiological effects of transcranial direct current stimulation: a review. Front Psychiatry. (2012) 3:110. doi: 10.3389/fpsyt.2012.00110

134. Woods AJ, Antal A, Bikson M, Boggio PS, Brunoni AR, Celnik P, et al. A technical guide to tDCS, and related non-invasive brain stimulation tools. Clin Neurophysiol. (2016) 127:1031-48. doi: 10.1016/j.clinph.2015.11.012

135. Jussila K, Junttila M, Kielinen M, Ebeling H, Joskitt L, Moilanen I, et al. Sensory abnormality and quantitative autism traits in children with and without autism spectrum disorder in an epidemiological population. $J$ Autism Dev Disord. (2020) 50:180-8. doi: 10.1007/s10803-019-04237-0 
136. Dhamne SC, Kothare RS, Yu C, Hsieh TH, Anastasio EM, Oberman L, et al. A measure of acoustic noise generated from transcranial magnetic stimulation coils. Brain Stimul. (2014) 7:432-4. doi: 10.1016/j.brs.2014.01.056

137. Taylor R, Galvez V, Loo C. Transcranial magnetic stimulation (TMS) safety: a practical guide for psychiatrists. Austr Psychiatry. (2018) 26:189-92. doi: 10.1177/1039856217 748249

138. Brunoni AR, Boggio PS, Ferrucci R, Priori A, Fregni F. Transcranial direct current stimulation: Challenges, opportunities, and impact on psychiatry and neurorehabilitation. Front Psychiatry. (2013) 4:19. doi: $10.3389 /$ fpsyt.2013.00019

Conflict of Interest: RL received travel grants and/or conference speaker honoraria within the last 3 years from Bruker BioSpin MR and Heel and has served as a consultant for Ono Pharmaceutical. He received investigator-initiated research funding from Siemens Healthcare regarding clinical research using PET/MR. He is a shareholder of the start-up company BM Health GmbH since 2019.
The remaining authors declare that the research was conducted in the absence of any commercial or financial relationships that could be construed as a potential conflict of interest.

Publisher's Note: All claims expressed in this article are solely those of the authors and do not necessarily represent those of their affiliated organizations, or those of the publisher, the editors and the reviewers. Any product that may be evaluated in this article, or claim that may be made by its manufacturer, is not guaranteed or endorsed by the publisher.

Copyright (c) 2021 Prillinger, Radev, Amador de Lara, Klöbl, Lanzenberger, Plener, Poustka and Konicar. This is an open-access article distributed under the terms of the Creative Commons Attribution License (CC BY). The use, distribution or reproduction in other forums is permitted, provided the original author(s) and the copyright owner(s) are credited and that the original publication in this journal is cited, in accordance with accepted academic practice. No use, distribution or reproduction is permitted which does not comply with these terms. 